\title{
Effect of Surface Hydrogenation on the Adsorption and Thermal Evolution of Nitrogen Species on Diamond(001) by Microwave $\mathrm{N}_{2}$ Plasma
}

Yusen Zheng, ${ }^{\mathrm{a} b, \mathrm{~b}+}$ Mohan Kumar Kuntumalla, ${ }^{\mathrm{b},+}$ Mohammed Attrash, ${ }^{\mathrm{b},+}$ Alon Hoffman,,${ }^{\mathrm{b},}$ and Kai Huang a,

a. Chemistry Program, Guangdong Technion-Israel Institute of Technology, 241 Daxue Road, Shantou, Guangdong Province, 515063, China

b. Schulich Faculty of Chemistry, Technion-Israel Institute of Technology, Haifa, 32000, Israel

+ Y. Z., M. K. K. and M. A. contributed to this work equally.

*Corresponding authors: A. H. (choffman@technion.ac.il) and K. H. (kai.huang@gtiit.edu.cn)

\section{Supporting Information}




\section{$\underline{\text { S1. Experimental Details }}$}

(a) Sample Cleaning and Hydrogenation: Type IIa single crystal diamond (001) $\left(7 \times 7 \times 0.3 \mathrm{~mm}^{3}\right)$ surface was exposed to microwave $\mathrm{H}_{2}$ plasma to remove the non-diamond components. The $\mathrm{H}_{2}$ flow rate, pressure, MW power and the duration of the hydrogenation were $250 \mathrm{sccm}$, 90 Torr, $5000 \mathrm{~W}$, and $20 \mathrm{~min}$, respectively. Next, a buffer layer of thickness $\sim 1 \mu \mathrm{m}$ was grown by microwave chemical vapor deposition $(2.5 \mathrm{GHz}, 6000 \mathrm{~W})$ using methane $\left(\mathrm{CH}_{4}\right)$ and hydrogen $\left(\mathrm{H}_{2}\right)$ as precursor gases at a gas pressure and flow rate of 140 Torr and 10:250 sccm $\left(\mathrm{CH}_{4}: \mathrm{H}_{2}\right)$, respectively. The diamond substrate temperature during the growth was $\sim 900{ }^{\circ} \mathrm{C}$. The good quality of the as-prepared hydrogenated diamond(001) is ensured by low energy electron diffraction and temperature-programmed desorption, as against published results. ${ }^{1}$

(b) Surface Nitridation: The hydrogenated diamond (001) was nitrided by microwave $\mathrm{N}_{2}$ plasma in-situ at room temperature for $15 \mathrm{~min}$. During the exposure to the microwave $\mathrm{N}_{2}$ plasma we estimate that the sample temperature was $\sim 120{ }^{\circ} \mathrm{C}$. The $\mathrm{N}_{2}$ flow rate, pressure, microwave power were maintained to $20 \mathrm{sccm}, 11$ Torr, and $1000 \mathrm{~W}$, respectively. The microwave $\mathrm{N}_{2}$ plasma activation was achieved by inserting and activating hydrogen in the system at a dynamic flow rate of $250 \mathrm{sccm}$ by the microwave plasma source for $5 \mathrm{~min}$, followed by the insertion of nitrogen and concurrently, the hydrogen flow was interrupted. This procedure was necessary in order to ignite the nitrogen plasma.

(c) XPS Measurement and Data Analysis: The as-nitrided sample was transferred into an ultrahigh vacuum system $\left(\sim 1 \times 10^{-9}\right.$ Torr in base pressure), followed by a brief anneal at $300{ }^{\circ} \mathrm{C}$ to remove possible contamination when exposed to ambient. XPS measurements were carried out using $\mathrm{Mg} \mathrm{K} \mathrm{K}_{\alpha}$ radiation $(1253.6 \mathrm{eV})$ at an incident angle of $55^{\circ}$ from the surface normal. Fitting of the XPS peaks was made using Shirley background subtraction and Gaussian-Lorentzian peak shape. $^{2}$ To extract the amount of surface nitrogen, we used the equation for the adsorption layer 
$\operatorname{model}^{3,4}$ :

$$
\frac{I_{N}}{I_{C}}=\frac{\mu_{N} A_{w}}{\mu_{C} \rho N_{a} \lambda} \sigma_{m}
$$

where $I_{N}$ and $I_{C}$ are the integrated photoelectron intensities of $\mathrm{N}(1 \mathrm{~s})$ and $\mathrm{C}(1 \mathrm{~s})$ respectively; the atomic sensitivity factors ratio of $\frac{\mu_{N}}{\mu_{C}}$ was taken as 1.87 for the $\mathrm{Mg} \mathrm{K}_{\alpha}$ source used in our XPS experiment; $\rho$ is the diamond mass density $\left(3.52 \mathrm{~g} \cdot \mathrm{cm}^{-3}\right) ;^{5} \mathrm{~N}_{\mathrm{a}}$ is the Avogadro constant, $\lambda$ is the mean free path for $\mathrm{C}(1 \mathrm{~s})$ photoelectrons in diamond (1.9 $\mathrm{nm}$ for $\mathrm{Mg} \mathrm{K}_{\alpha}$ radiation $^{6}$ ); $\mathrm{A}_{\mathrm{w}}$ is the carbon atomic weight and $\sigma_{\mathrm{m}}$ is the nitrogen surface concentration in the unit of atoms $/ \mathrm{cm}^{2}$. In the main text, we report the nitrogen amount in the unit of monolayer (ML), in which 1 ML is defined as $1.60 \times 10^{15}$ atoms $/ \mathrm{cm}^{2}$, i. e. equivalent to the atomic density of surface carbon on diamond(001).

(d) TPD Measurement and Data Analysis: In the vacuum, the sample was heated at the rate of $1.6^{\circ} \mathrm{C} / \mathrm{s}$, and the temperature was measured by an optical pyrometer. The partial pressure of desorbed species was monitored by a mass spectrometer. To extract the activation energy of desorption from TPD, we followed the first order Redhead equation ${ }^{7,8}$ :

$$
E_{\text {des }}=R T_{\text {peak }}\left[\ln \frac{v \cdot T_{\text {max }}}{\beta}-\ln \frac{E_{\text {des }}}{R T_{\text {peak }}}\right]
$$

where $\ln \frac{E_{\text {des }}}{R T_{\max }}$ is taken as $3.46 ;{ }^{8} \mathrm{R}$ is the ideal gas constant; $\mathrm{T}_{\text {peak }}$ is the peak temperature in TPD; $\beta$ is the heating rate; $v$ is the pre-exponential factor.

\section{S2. Additional XPS Data in the C(1s) and N(1s) Regions}

In Figure S1 and S2, we document the raw XPS data for C(1s) and N(1s) states of the hydrogenated diamond sample before nitridation, after nitridation, and annealed at progressively increased temperatures up to $1000{ }^{\circ} \mathrm{C}$. Refer to the main text for analysis and discussion. 

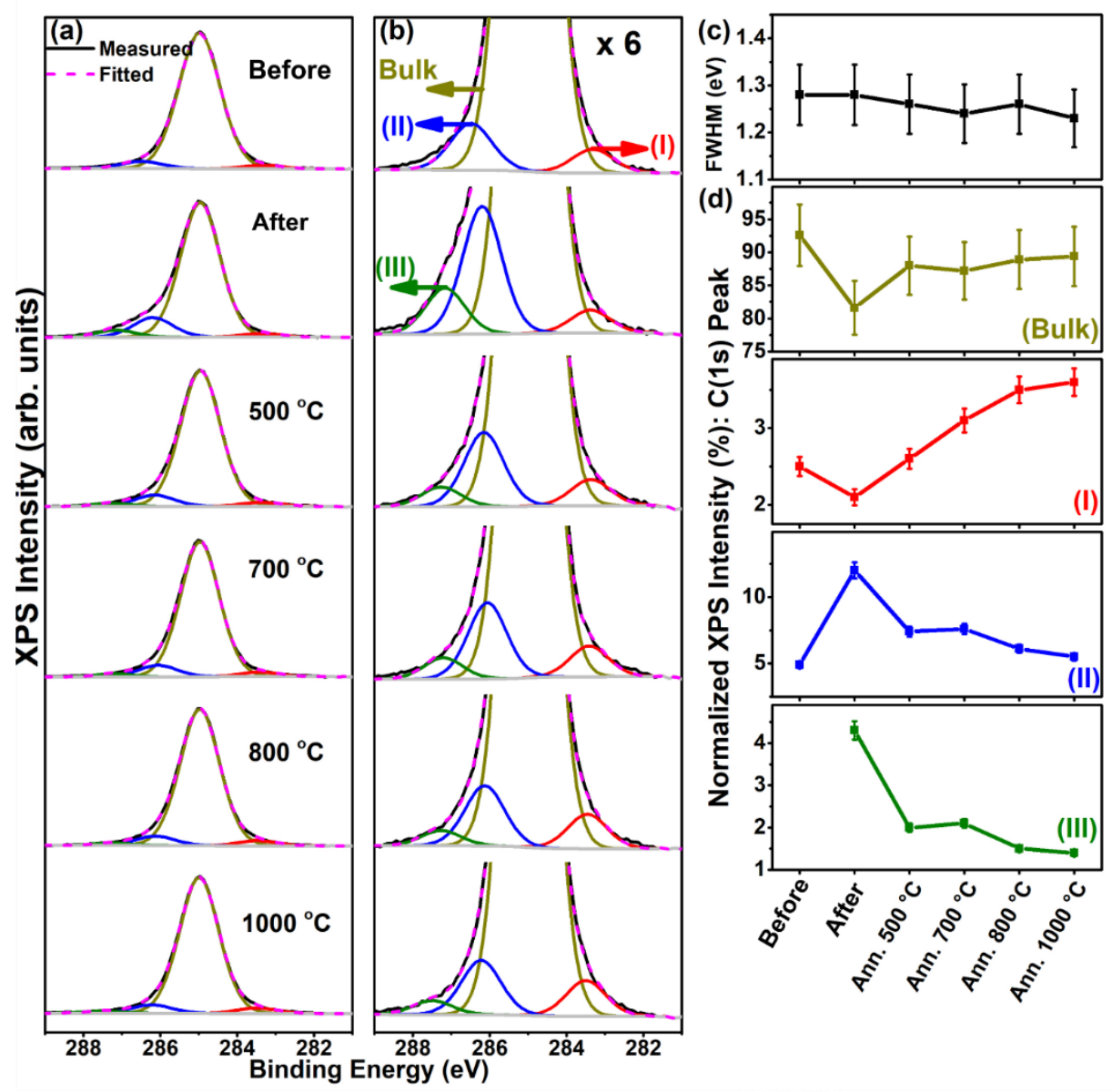

Figure S1. (a) C(1s) XP spectra obtained from before microwave $\mathrm{N}_{2}$ plasma, after microwave $\mathrm{N}_{2}$ plasma, and subsequently annealed at temperatures as specified; (b) $\times 6$ magnified y-axis spectra of $\mathrm{C}(1 \mathrm{~s}) ;(\mathrm{c}) \mathrm{C}(1 \mathrm{~s})$ FWHM in different annealing temperature; (d) Normalized C(1s) XPS intensity against to C(1s) peak. 
(a)

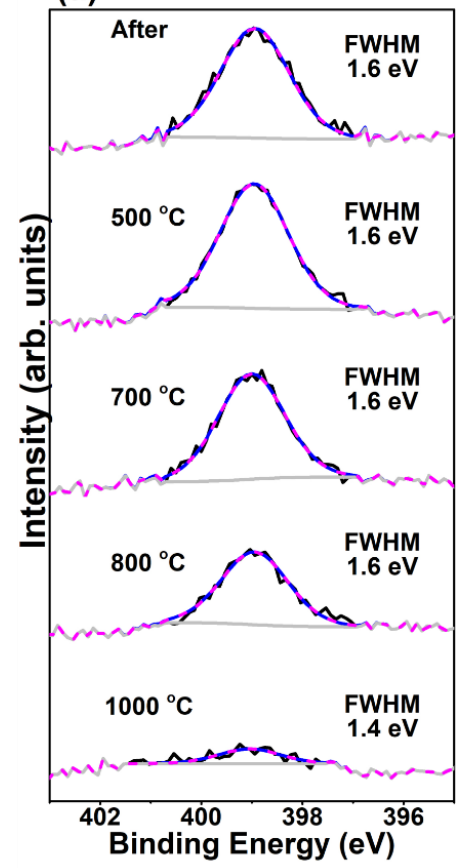

(b)

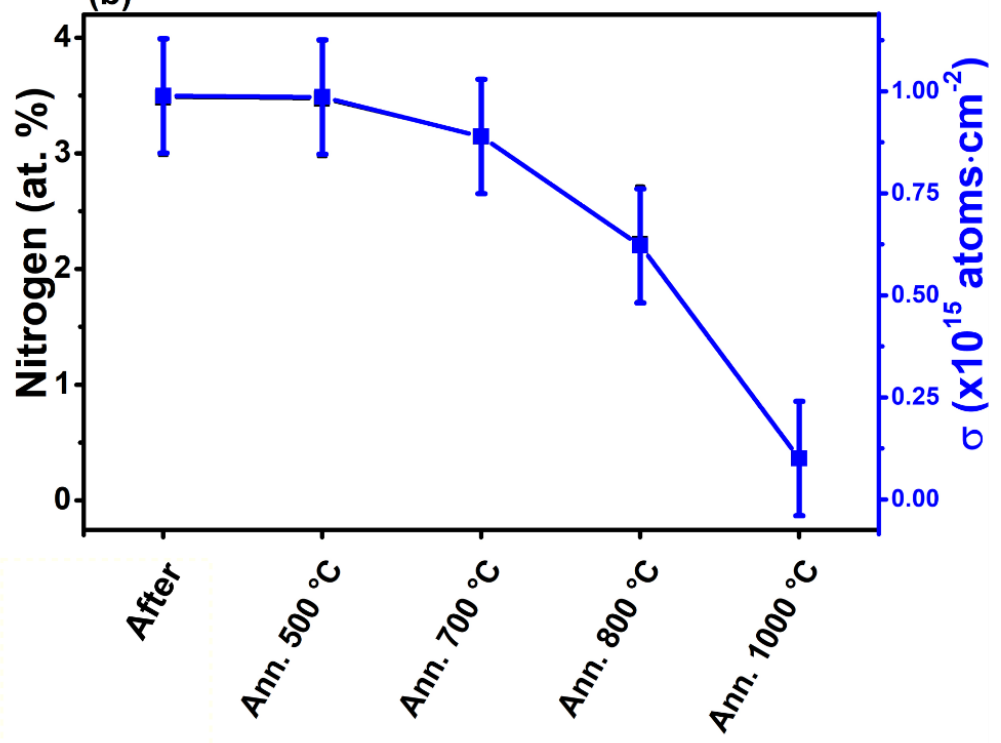

Figure S2. (a) N(1s) XP spectra obtained from after MW( $\left.\mathrm{N}_{2}\right)$ treatment and subsequently annealed sample, (b) surface nitrogen amount as a function of the anneal temperature.

\section{$\underline{\text { S3. Additional DFT Results on Computed C(1s) Core-level Shift by Surface Nitridation }}$}

The 1s core-level shift of surface carbons by nitridation was computed in the framework of the "initial state" approximation. ${ }^{9,10}$ On the hydrogenated diamond(001), the 1 s core state of the nitrided surface carbon was computed to have increased by $0.13 \mathrm{eV}$ in binding energy for h- $\mathrm{N}_{2}(\mathrm{ad})$ and $0.39 \mathrm{eV}$ for $\mathrm{v}-\mathrm{N}_{2}(\mathrm{ad})$. The initial state approximation relates the chemical shift to the difference in eigenvalues of core-electron Kohn-Sham orbitals of the surface carbons; other factors, such as band bending ${ }^{11}$ and core-hole screening/relaxation, ${ }^{12}$ are ignored. Hence, we consider that the computed increases of $0.13 \mathrm{eV}$ for $\mathrm{h}-\mathrm{N}_{2}(\mathrm{ad})$ and of $0.39 \mathrm{eV}$ for $\mathrm{v}-\mathrm{N}_{2}(\mathrm{ad})$ are in qualitative agreement with the shift of $1.5 \mathrm{eV}$ and $2.1 \mathrm{eV}$ in the $\mathrm{C}(1 \mathrm{~s})$ level by XPS. 
(a)

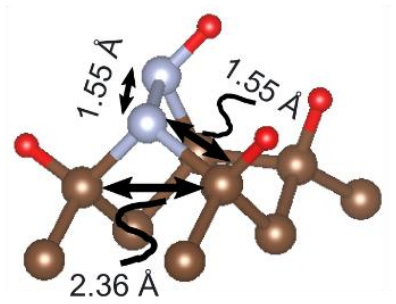

$$
E_{(\text {ads })}=+3.57 \mathrm{eV}
$$

(c)

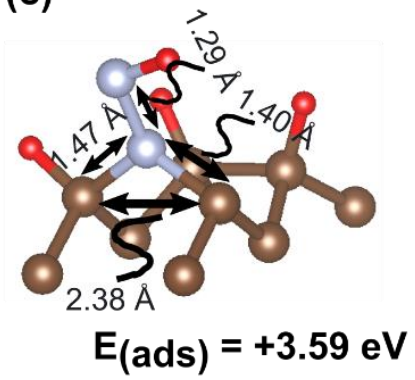

(b)

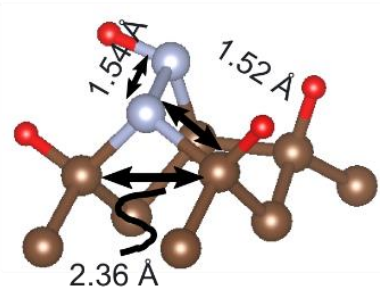

$$
E_{(\text {ads })}=+3.62 \mathrm{eV}
$$

(d)

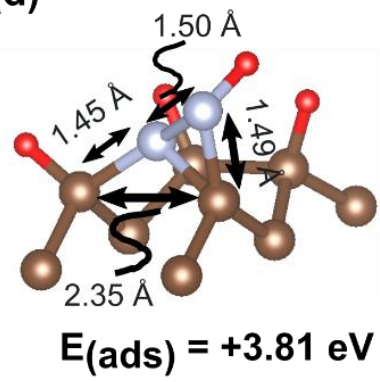

Figure S3. Computed geometries of $\mathrm{N}_{2} \mathrm{H}(\mathrm{ad})$ on hydrogenated diamond(001).

In Figure S3, we present four computed geometries, as resulted from structural relaxation of geometries that are gently deviated from $\mathrm{h}-$ and $\mathrm{v}-\mathrm{N}_{2}(\mathrm{ad})$. The heats of adsorption are reported in each panel. In all cases, a surface hydrogen is found to be abstracted to be bound to a nitrogen atom to form $\mathrm{N}_{2} \mathrm{H}(\mathrm{ad})$.

\section{S5. Additional DFT Results on the Adsorption and Desorption of $h-\mathrm{N}_{2}$ (ad) on Pristine} Diamond(001)

Figure $\mathrm{S} 4 \mathrm{a}$ and $\mathrm{S} 4 \mathrm{~b}$ describe the adsorption of $\mathrm{N}_{2}(\mathrm{ad})$ on pristine diamond(001), as first reported in our recent work ${ }^{13}$ and repeated here briefly. The $\mathrm{N}_{2}(\mathrm{ad})$ adopts a horizontal geometry, spanning two carbon dimers in the same row. The carbon dimers open up their $\pi$-bonds upon adsorption to form $\mathrm{C}-\mathrm{N}$ single bonds with $\mathrm{N}_{2}(\mathrm{ad})$, while maintaining the $\sigma$ bond of the $\mathrm{C}-\mathrm{C}$ dimer. The $\mathrm{N}-\mathrm{N}$ bond 
within $\mathrm{N}_{2}(\mathrm{ad})$ is of the nature of a single covalent bond. Our interpretation is based on the interatomic separation and charge analysis. First, the C-C, C-N and N-N separations are $1.51 \AA, 1.53$ $\AA$ and $1.57 \AA$, respectively; c.f. typical covalent lengths of C-C, C-N and N-N single bonds are $1.54 \AA, 1.47 \AA, 1.45 \AA$, respectively. ${ }^{14}$ Second, the insets in Figure S4b show close resemblance of the $\sigma$ character of C-C, C-N and $\mathrm{N}-\mathrm{N}$ bonds when analyzing the spatial distribution of electron charge in the energy windows of -3.3 to $-2.3 \mathrm{eV}$ and of +4.6 to $3.2 \mathrm{eV}$. The adsorption energy is $+0.66 \mathrm{eV}$ (endothermic!), which is consistent with the fact that molecular $\mathrm{N}_{2}$ needs to be activated as plasma to attach to the diamond surface. It is found that the nitridated surface carbon experiences virtually minimal shift in the 1 s core state, i.e. an increase of $0.02 \mathrm{eV}$ in binding energy with respect to the bulk carbon.

(a)

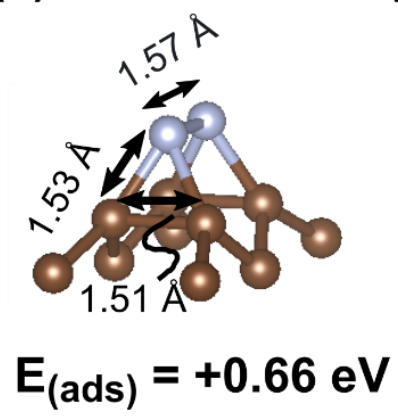

(b)

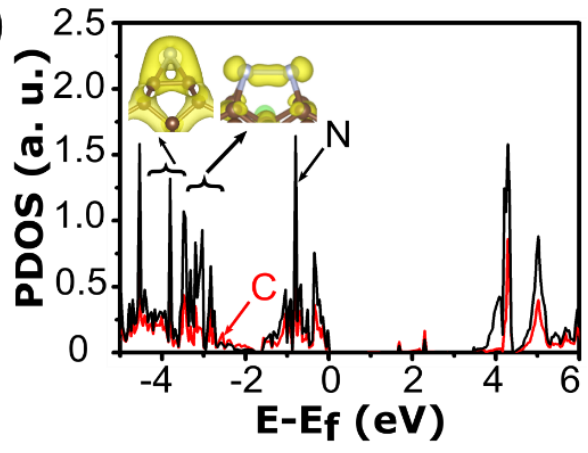

(c)

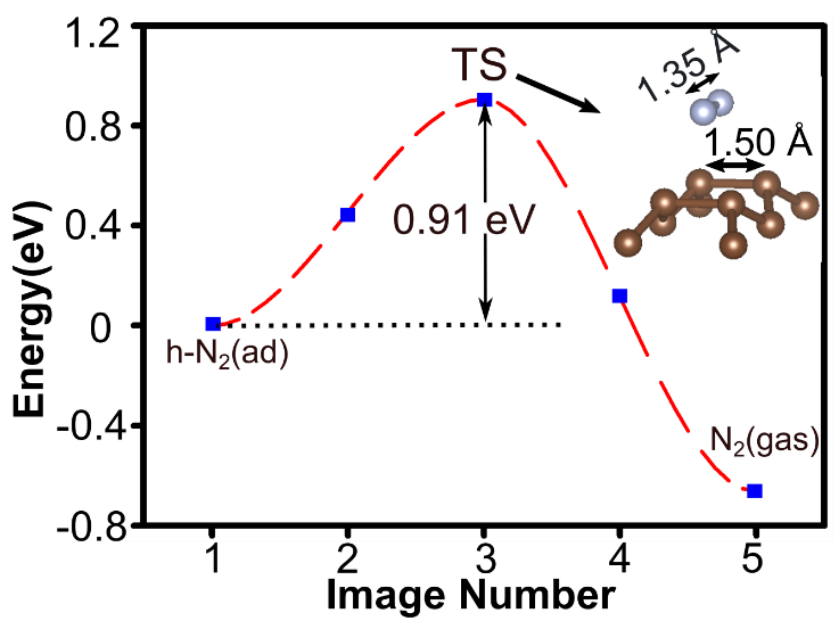

Figure S4. Panel (a) shows the adsorption structure of horizontal $\mathrm{N}_{2}(\mathrm{ad})$ on pristine diamond(001). The 
heat of adsorption is $+0.66 \mathrm{eV}$. Panel (b) presents the analysis of the projected density-of-states (PDOS), and the electron-charge at -3.3 to $-2.3 \mathrm{eV}$ and of +4.6 to $3.2 \mathrm{eV}$. Note that the isosurface of the electroncharge is $0.010 \mathrm{e}^{-} / \mathrm{bohr}^{3}$. In panel (c), the computed minimum energy path of desorption is given, along with the transition state geometry. The desorption barrier is computed as $0.91 \mathrm{eV}$.

We also calculated the minimum energy path (MEPs) of desorption for $h-\mathrm{N}_{2}(\mathrm{ad})$ from pristine diamond(001). Several geometries of final states were explored, including a horizontal and a vertical $\mathrm{N}_{2}$ about $3 \AA$ away from the substrate (effectively in the gas phase); the computation, however, converged to the same path that proceeds as a simple elementary step. As presented in Figure S4c, the desorption pathway features the synchronized shortening of both N-N and C-C separations as the N-dimer moves away the surface. This feature is best captured in the computed geometry of transition state (TS), in which the N-dimer is lifted $1.35 \AA$ further away the surface, while the N-N and C-C separations are shortened by $0.22 \AA$ and $0.01 \AA$, respectively. The computed barrier is as low as $0.91 \mathrm{eV}$, which is significantly lower than the experimental value of $\sim 2.42 \mathrm{eV}$ by TPD.

\section{References}

(1) Bobrov, K.; Shechter, H.; Folman, M.; Hoffman, A. Deuterium adsorption-desorption from diamond (100) single crystal surfaces studied by TPD. Diam. Relat. Mater. 1998, 7, 170-176.

(2) Seah, M. P.; Briggs, D. Practical Surface Analysis: Auger and X-ray Photoelectron Spectroscopy. John Wiley \& Sons. 1990.

(3) Madey, T. E.; Yates Jr, J. T.; Erickson, N. E. ESCA study of fractional monolayer quantities of chemisorbed gases on tungsten. Chem. Phys. Lett. 1973, 19, 487-492.

(4) Carley, A. F.; Roberts, M. W. An X-ray photoelectron spectroscopic study of the interaction of oxygen and nitric oxide with aluminium. Proc. R. Soc. Lond. A, 1978, 363, 403-424.

(5) Asmussen, J.; Reinhard, D. K. Diamond films handbook. CRC Press. 2002, pp. 5.

(6) Evans, S.; Pritchard, R. G.; Thomas, J. M. Escape depths of X-ray $\left(\mathrm{Mg} \mathrm{K}_{\alpha}\right)$-induced photoelectrons and relative photoionization cross sections for the $3 p$ subshell of the elements of the first long period. J. Phys.

C. Solid State Phys. 1977, 10, 2483.

(7) Redhead, P. A. Thermal desorption of gases. Vacuum. 1962, 12, 203-211.

(8) King, D. A. Thermal desorption from metal surfaces: A review. Surf. Sci. 1975, 47, 384-402.

(9) Lizzit, S.; Baraldi, A.; Groso, A.; Reuter, K.; Ganduglia-Pirovano, M. V.; Stampfl, C.; Scheffler, M.; Stichler, M.; Keller, C.;Wurth, W.; Menzel, D. Surface core-level shifts of clean and oxygencovered $\mathrm{Ru}(0001)$. Phys. Rev. B. 2001, 63, 205419.

(10) Birgersson, M.; Almbladh, C. O.; Borg, M.; Andersen, J. N. Density-functional theory applied to 
$\mathrm{Rh}(111)$ and $\mathrm{CO} / \mathrm{Rh}(111)$ systems: geometries, energies, and chemical shifts. Phys. Rev. B. 2003, 67, 045402 .

(11) Zhang, Z.; Yates Jr, J. T. Band bending in semiconductors: chemical and physical consequences at surfaces and interfaces. Chem. Rev. 2012, 112, 5520-5551.

(12) Bagus, P. S.; Ilton, E. S.; Nelin, C. J. The interpretation of XPS spectra: Insights into materials properties. Surf. Sci. Rep. 2013, 68, 273-304.

(13) Zheng, Y.; Hoffman, A.; Huang, K. Atomistic insight into nitrogen-terminated Diamond (001) surfaces by the adsorption of $\mathrm{N}, \mathrm{NH}$, and $\mathrm{NH}_{2}$ : a density functional theory study. Langmuir. 2021, 37, 62486256.

(14) Lide, D. R. CRC Handbook of chemistry and physics. CRC press, 2004, 85. 